\title{
Perceptions about Epilepsy in the Limpopo Province of the Republic of South Africa
}

\author{
ML Mangena-Netshikweta, M.Cur, Department of Advanced Nursing Science, \\ University of Venda for Science and Technology
}

\section{Acknowledgment}

All participants are thanked for sharing their perceptions with the researcher and the field workers are thanked. Without their contributions this research would not have been possible. Each nurse who acted as a field worker during the data gathering phase is thanked for facilitating and maintaining this time-consuming process. These contributions made the research feasible.

\section{Introduction and background information}

In rural African communities, there are widespread beliefs that epilepsy is due to possession of bewitchment by evil spirits or the devil. There is also a belief that the transmission of the disease is by physical contact, such as by saliva (Osuntokun 1990:106). In central Africa, as well as in Sub-Saharan Africa, epilepsy is attributed to the presence of a lizard in the brain, and epileptic fits occur whenever the lizard moves ( Haddock 1993:118 ; Nyame 1997:143). Such perceptions toward epilepsy and a person with epilepsy, in indigenous Africa, are invariably unfavourable and unfounded as they reflect mythical beliefs about the disease.

Most professionals know epilepsy to be a nervous disorder causing the patient to suffer convulsions, with or without the loss of consciousness (Oxford Handy Dictionary 1991). People with epilepsy tend to view themselves and their condition as unacceptable to themselves and to others and are thus less likely to seek support (Uys \& Middleton 1997:479).

Despite its high prevalence, epilepsy, like HIV/AIDS, continues to be socially stigmatised. Those suffering from epilepsy become ostracised and discriminated against by many communities in England, India and Africa (Brains et al 1992:14; Eisenschenk \& Gilmore 1999:31).

Literature searched reveal that considerable research has been done on the incidence of epilepsy (and especially of seizures), but no previous research report could be traced which had studied public perceptions of persons with epilepsy in the Limpopo Province (LP) of the Republic of South
Africa (RSA), although epilepsy is known to be a common neurological disorder in this province.

\section{The purpose of the study}

The purpose of the survey was to ascertain the feelings and the perceptions the communities have about epilepsy and about persons suffering from epilepsy, so that the public could differentiate between myths, superstitions and facts associated with epilepsy. Based on the findings of this research, more effective health education could be launched to enhance the quality of life of persons suffering from epilepsy, in this province.

\section{Objectives of the study}

This exploratory descriptive survey attempted to:

- identify the beliefs of rural communities in the Limpopo Province about epilepsy;

- $\quad$ ascertain the perceptions about the treatment(s) deemed to be most effective for persons suffering from epilepsy in this area ;

- $\quad$ ascertain the perceptions about social interactions with persons suffering from epilepsy;

- determine knowledge of rural communities about epilepsy.

\section{Research design and method}

A non-experimental, exploratory, descriptive design was used to obtain data by means of questionnaires. Information was obtained concerning perceptions about epilepsy and treatment of persons suffering from epilepsy in the Limpopo Province. This was an exploratory study because no earlier studies on this topic in this area could be traced, 
and it was descriptive because it aimed merely to ascertain and describe persons' perceptions about epilepsy, knowledge of the respondents about care given to a person with epilepsy, during a seizure attack, as well as perception of communities and treatment modalities.

\section{Population and research sample}

The population consisted of the communities visiting clinics in sub-district of Mutale under Vhembe District. The research sample comprised 1010 black men and women from community members who visited designated clinics during the period of conducting this study. A non-probability convenience sample was used. A convenience sampling consists of using the most readily available or most the convenient group of people for the sample ( Polit \& Hungler 1997:244). Criteria for inclusion into the research population was that, men and women between the ages of 30 to 70 years who visited designated clinics during the period between July 2000 and May 2001, comprised the population of this research. This age group was selected because such people care for epileptic persons in the communities served by the clinics participating in this study. No sampling selection procedures were used, as each adult visiting the participating clinics during the period of conducting the survey was requested to participate in this study. Participation remained voluntary. No participant was remunerated for his/her inputs. All participants were assured that their answers would be anonymous because their names would not appear anywhere on the questionnaire. All responses were treated as confidential. Using a convenience sample might have influenced the generalisability of the research findings, because no assurances can be given that those 1010 persons who participated had the same opinions as those who did not participate. However, a large number (1010) of participants was used to counteract possible prejudices which might occur amongst the minorities in the community studied.

\section{Research instrument}

Based on the literature review open-ended questions were designed to obtain participants' perceptions about epilepsy. The questions were phrased as simply as possible. The questions were translated into Tshivenda language, spoken by local people attending the three participating clinics, and by the nurses working in these clinics. The questions were compiled and translated by the researcher, who speaks both languages. Both the English and Tshivenda versions were studied by an expert in both languages to ensure that the translated question conveyed the intended meaning.

\section{Reliability and validity of the research instrument}

The reliability of a measure denotes the consistency of measures obtained in the use of a particular instrument and is an indication of the extent of random error in the measurement method (Burns \& Grove 2001:395). The reliability of the questionnaire was enhanced by checking and rechecking the translated items interpretations by academ- ics, nurses and health care clients who did NOT form part of the research sample. As similar responses were obtained from these three diverse groups of persons, it was accepted that the questionnaire succeeded in obtaining peoples' perceptions about epilepsy.

The validity of an instrument is a determination of the extent to which the instrument actually reflects the abstract construct being examined... validity addresses the appropriateness, meaningfulness, and usefulness of the specific inferences made from instrument scores (Burns \& Grove 2001:399).

The content-related validity of the questionnaire items (based on in-depth literature reviews) was judged by a number of academics, nurses and health care clients to be relevant to the topic of identifying persons' perceptions about epilepsy in the Limpopo Province.

\section{Data collection}

A non- experimental, exploratory descriptive survey was used to collect information about perceptions of people towards epilepsy in the Limpopo Province, including their knowledge of and care rendered to persons suffering from epilepsy.

Registered and enrolled nurses in each clinic participating in the survey (from the sub-district of Mutale under Vhembe District) acted as voluntary field workers. The researcher visited each clinic under this sub-district, explained the need for the research and promised that each participating clinic would receive a copy of the research report. It was explained that the data should enable nurses to provide more effective health care and health education to persons suffering from epilepsy, and to their care- takers. The administration of the questionnaires aimed at identifying people 's perceptions about epilepsy and about persons suffering from epilepsy in these communities. The registered and enrolled nurses interviewed adults who could not read and/ or write using the questionnaire as a structured interview and entered their responses on a questionnaire in the same way that the participant would have done if he/she could read and write. In these cases the nurses assured confidentiality of responses and reassured the participants about the confidentiality of their responses.

\section{Data analysis}

The SPSS software was used to analyse the data obtained from the questionnaires used during the structured interviews with 1010 men and women who visited the designated clinics during the period of conducting this study.

\section{Research results Biographic Information}

As many as $88,5 \%$ of the respondents' ages ranged from 30 to 60 years. Their major occupation was that of labourer $(88.7 \%)$. More females $(58.8 \%)$ than males participated $(47,6 \%)$ in this survey. There were slightly more Zionist 
(89.7\%) reportedly did not know

\begin{tabular}{|c|c|c|c|}
\hline & characteristics & NO & $\%$ \\
\hline \multirow[t]{4}{*}{ Age (yrs) } & $30-40$ & 316 & 31.2 \\
\hline & $41-50$ & 377 & 26.0 \\
\hline & $51-60$ & 218 & 21.5 \\
\hline & 61 and above & 99 & 9.8 \\
\hline \multirow[t]{2}{*}{ Sex } & male & 606 & 47.6 \\
\hline & female & 860 & 58.8 \\
\hline \multirow[t]{2}{*}{ Religion } & Christian & 576 & 33.1 \\
\hline & Zionist & 781 & 53.7 \\
\hline \multirow[t]{4}{*}{ Marital status } & married & 890 & 79.8 \\
\hline & widow & 162 & 11.2 \\
\hline & single & 76 & 5.2 \\
\hline & divorced & 70 & 4.8 \\
\hline \multirow[t]{5}{*}{ Level of education } & illiterate & 959 & 86.1 \\
\hline & read \& write & 51 & 13.9 \\
\hline & grade 8 and above & 21 & 1.4 \\
\hline & financial independent & 49 & 8.0 \\
\hline & subsistence level income & 999 & 92.2 \\
\hline \multirow[t]{5}{*}{ Occupation } & farming & 42 & 8.0 \\
\hline & house wife & 475 & 51.0 \\
\hline & labourer & 998 & 88.7 \\
\hline & dependent & 27 & 1.9 \\
\hline & government employee & 9 & 0.6 \\
\hline
\end{tabular}

what caused epilepsy while $(51,6)$ stated that an individual is born with it, even though $(55,5 \%)$ maintained that it was probably caused by evil spirits, $(60.1 \%)$ believed that epilepsy was a curse from God, and $(2,0 \%)$ mentioned natural causes, such as accidents.

\section{Perceptions about the treatment of persons suffering from epilepsy}

Religious charms on the body was indicated by $(49.9 \%)$ of the respondents to constitute an effective means of treating persons suffering from epilepsy. The precise nature of these charms were not indicated by any respondent, nor where or how these charms could be obtained. Medical drugs were reportedly the least favoured, and were seen as the least successful, method of treatment for epilepsy. As many as $69.9 \%$ of the respondents favoured traditional medicines (unspecified) rather than modern drugs for treating persons suffering from epilepsy. This finding could imply that the majority of epileptic sufferers in the community did not receive and/or did not take their pre-

believers $(53,7 \%)$ than Christian believers $(33,1 \%)$ whilst the majority were non-Christian but had their own ways of worshipping their gods $(53.7 \%)$. The majority of the respondents were married $(79,8 \%)$, and illiterate $(86.1 \%)$. Only (8.0\%) of the respondents could be classified as being financially independent, but ( $92.2 \%$ ) reportedly had only subsistence level incomes. Only $(1,4 \%)$ had secondary education. The biographic information is summarised in table 1.

\section{Respondents' knowledge about epilepsy}

Different names were used for epilepsy in the community, including tshiivha, tshifakhole, tshiririvha. Only $10 \%$ of the respondents indicated that the disorder is called "epilepsy ".

Of the participants, $90.0 \%$ indicated that they knew about or had read about epilepsy. $70.9 \%$ had witnessed a seizure during their lifetime, but only $38,2 \%$ admitted that they had a family member suffering from epilepsy.

\section{Respondents' perceptions about epilepsy \\ Perceptions about the nature of epilepsy}

Only $(4.9 \%)$ of the respondents considered epilepsy to be a hereditary condition. The majority of the respondents scribed anti-convulsive treatments

The majority of the respondents indicated that epilepsy was incurable, especially if these persons sustained burns during seizures - a real risk in this area of the Limpopo Province where the majority of households use open fires to prepare their meals.

On ways in which society could care for persons suffering from epilepsy, only $20.4 \%$ of the respondents gave their opinions, whist the majority $(79,6 \%$ ) claimed not to know how this could be achieved. Only $45.7 \%$ of the respondents believed that sacrifice to the ancestors would be beneficial while $9,5 \%$ indicated that patients need to be prayed for.

The majority of the respondents did not know what care to render during seizures $87,1 \%$, although $5.8 \%$ indicated that they would guard and protect the person having the convulsion from hurting him/herself. Only $4.5 \%$ indicated that they would splash chilli water over the victim's face to frighten away the evil spirit causing the seizures. A small percentages of those interviewed indicated that they would give holy water to the victim $0,9 \%$. Indigenous medicines were favoured by $69.9 \%$ of the respondents, but the types of traditional medicines were not specified.

\section{Perceptions about social interactions with persons suffering from epilepsy}

The study showed that the men and women reported simi- 
Table. 2: Question: Do you know the causes of epilepsy?

\begin{tabular}{|l|l|}
\hline Result 1010 responses & Yes \% \\
\hline Don't know & 89.7 \\
Evil spirits & 55.5 \\
Punishment from God & 60.1 \\
Born with it & 51.6 \\
Accident & 2.0 \\
\hline
\end{tabular}

Table. 3: Question : How should society take care of persons with epilepsy?

\begin{tabular}{|l|l|}
\hline Result 1010 responses & $\%$ \\
\hline Don't know & 79.6 \\
Give sacrifices to the spirits & 45.7 \\
Pray for them & 9.5 \\
Give charms & 49.9 \\
\hline
\end{tabular}

\section{Table.4 Question: Do you know what to do for someone having a convulsive attack ?}

\begin{tabular}{|l|l|}
\hline Result 1010 responses & $\%$ \\
\hline Don't know & 87.1 \\
Protect guard patient & 5.8 \\
Give herbal medicine & 69.9 \\
Give holy water & 0.9 \\
Splash chilli water over face & 4.5 \\
\hline
\end{tabular}

lar perceptions about epilepsy and about persons suffering from epilepsy, and followers of both the Christian and zionist reported similar perceptions about epilepsy. However, older respondents (above 60 years of age) reported more negative perceptions than those aged 40 or younger. Surprisingly, those respondents who had family members suffering from epilepsy did not portray markedly different perceptions from those who did not have affected family members.

The Limpopo Province's rural communities perceived epilepsy as a scaring disorder because of its alleged association with evil spirits and witchcraft. As a result of these perceptions (and superstitions), persons with epilepsy in rural African countries, might suffer from social deprivation and discrimination. Of the participants, $(90,0 \%)$ indicated that they heard or read about epilepsy. In spite of these beliefs and fears as many as $(98,2 \%)$ of the respondents indicated that persons suffering from epilepsy should be kept in their homes and should not be kept away from their communities. The majority of the respondents $(89,7 \%)$ considered contact during convulsions to be the most significant method of transmission, explaining why contact with persons during seizures would be avoided at all costs. Although $(70,6 \%)$ of the respondents would not employ a person suffering from epilepsy, $52,7 \%$ were willing to work with such a person, and $50,8 \%$ would shake hands with someone having the disorder. Only $40,2 \%$ of the respondents were willing to establish friendships with persons suffering from epilepsy, but only $3,4 \%$ reportedly had such friendships at the time when the data was collected. Surprisingly $70,6 \%$ of the respondents would not object to their children playing with children suffering from epilepsy. However, they agreed that they would instruct their children to run away from their playmates during seizure attacks or if convulsions occurred probably because the majority 89,7 regarded physical contact during convulsions as being the major means of contracting epilepsy. This perception might explain why many persons sustain severe burns during seizures-accounting their relatives' fears of assisting them or of pulling them out of fires during seizures. Lee and Lemmer (1995:199) reported similar perceptions among respondents, about the transmissions of epilepsy by direct physical contact with persons or their secretions during seizures.

The response of the interviewees from the rural community during this survey had succeeded in registering the prevalent beliefs on and perceptions toward epilepsy, concerning the background of the community studied, it should be noted that the characteristics that were most relevant to the attitudinal study were the high illiteracy rate of $86,1 \%$ and the prevalence of epilepsy in the community, where the majority of those suffering from epilepsy were not receiving anticonvulsant treatment, because of the close social contacts and interactions within the community. The majority of the respondents in this study had witnessed seizure attacks $70,9 \%$, but were not aware of the causes of the disease $89,0 \%$. Although epilepsy was still feared and dreaded in the rural community studied, the researcher was impressed by the fact that the respondents showed reasonable understanding and tolerance to the person with epilepsy, particularly if the sufferer did not exhibit aggressive tendencies and did not have after signs of affection by the disease such as mental retardation.

There was a particular sympathy for children with the disease, both from parents and the general public. It is interesting to note that more people $70,6 \%$ were willing to allow their children to play with peers having epilepsy, compared to the experience of some ethnic groups in Nigeria (Odeku and Dada ethnic groups ) where almost $84,9 \%$ of the respondents in the two studies conducted in Nigeria, opposed such an association, probably due to the belief that epilepsy is a contagious disorder (Danesima 1994:26; Osuntokun 1990:104).

Only $14,9 \%$ of the respondents were willing to allow someone suffering from epilepsy to marry a member of their fami- 


\begin{tabular}{|l|l|l|c|}
\hline characteristics & Yes & No & No response \\
\hline Have you heard or read about epilepsy? & 90.0 & 10.0 & - \\
Have you seen someone with seizure attack? & 70.9 & 13.8 & - \\
Do you have a family member with epilepsy? & 38.2 & 61.8 & - \\
Is epilepsy hereditary? & 4.9 & 89.0 & - \\
Is epilepsy contagious? & 89.7 & 10.3 & - \\
Are you willing to work with an epileptic person? & 52.7 & 46.8 & 1.2 \\
Are you willing to establish relationships with persons suffering from epilepsy? & 40.2 & - & 56.4 \\
Would you house a person with epilepsy? & 67.2 & 32.2 & 0.6 \\
Hiding a person with epilepsy from the public? & 1.8 & 98.2 & - \\
Is epileptic person capable to support the family? & 17.0 & 53.0 & - \\
Would you shake hands with an epileptic person as a friend? & 50.8 & 9.2 & 40.0 \\
Do you object to your own child associating with persons with epilepsy? & 40.2 & 7.06 & 0.7 \\
Would you employ an epileptic person? & 29.0 & 70.6 & 0.4 \\
Would you allow your family member to marry an epileptic person? & 14.9 & 85.1 & - \\
Would you consider an epileptic person well controlled/cured? & 39.7 & 60.3 & \\
\hline
\end{tabular}

lies, $85,1 \%$ cited the perceived contagious nature of epilepsy as the reason for such objections. The respondents believed that the person with epilepsy was incapable of being gainfully employed and generating an income to support a family $53,0 \%$. DeLorenzo (1998:48) reported strong perceptions against matrimonial associations with persons suffering from epilepsy. This researcher reported cases where husbands divorced their wives, or wives ran away, on discovering that the partner is suffering from epilepsy. When asked if they would consider a person with epileptic fits well controlled/cured from his/her illness, $39,7 \%$ answered in the affirmative, while $60,3 \%$ stated the disorder was incurable.

The wearing of amulets and/or specific bangles to prevent convulsions might aggravate the social isolation and stigmatisation of many persons suffering from epilepsy who live in rural communities in Africa, including the Limpopo Province. Carod (1998:1067) indicates that in other African countries, a person suffering from epilepsy might face such serious social ostracism as to become an outcast from his/ her community. Chung (1995:491) asserts that in Taiwan and India, social rejection occurs when uncontrolled seizures result in severe burns/deformities and/or mental retardation. Similar perceptions about epilepsy were obtained during this survey in the Limpopo Province of the RSA, where a patient has no supporter and care from the family members.

In the Limpopo Province of the RSA, like other parts of Africa, indigenous medicine in the form of herbal remedies, holy water or charms to wear on the body, given by faith healers/spiritual healers were commonly used in the community to cure /treat or prevent epilepsy. However, this was not the evidence in this study. This may be due to a tendency of respondents to conceal the information, be- cause the majority of the respondents are illiterate $86,1 \%$, as they cannot read nor write, probably because they could not trust the voluntary field workers who were responsible for collecting data.

\section{Limitations of the research}

The descriptive exploratory survey attempted to identify the perceptions about epilepsy and about persons suffering from epilepsy in selected rural areas of Venda only. This geographic limitation might limit the generalisability of the research results to other rural areas, and/or to other provinces of the RSA. However, these research results should provide a point of departure to conduct similar research in other geographic areas.

Another limitation might be related to the research population being limited to those adults who visited specific clinics in designated rural areas during one calendar year when the data was collected. However, it was attempted to overcome this limitation by using a large sample, comprising 1010 respondents.

\section{Recommendations}

Health education efforts in the rural areas of the Limpopo Province should strive to convey knowledge about the causes of epilepsy as well as about the nature of anti-convulsive drugs. Much human suffering could be avoided if only persons witnessing seizures could rescue the victims from falling into fires-unlikely occurrences while the majority of the community members perceive epilepsy to be contagious during seizures.

Future research should strive to identify the health care 
professionals' perceptions about epilepsy and about persons suffering from epilepsy. If the health care professionals portray similar perceptions, then health education efforts should be geared towards these professional groups, prior to attempting to provide effective health education to the communities as such.

Health education efforts should also stress the importance of treating potential causes of seizures such as high temperatures and pre-eclampsia/eclampsia during pregnancy. Effective immunization against childhood diseases, including measles, could reduce the incidence of seizures in any community. Neglected gastro-intestinal conditions could cause convulsions as a result of sever fluid and electrolyte imbalances. Malaria (endemic in the geographic area where the survey was conducted) could cause convulsions as a result of hyperpyrexia or in cases of cerebral malaria. If health education efforts could succeed in establishing these links between seizures and physical ailments, more persons might be assisted (and saved from sustaining severe burns) during seizures.

\section{Conclusion}

Epilepsy might be a public health problem of unknown proportions in many developing countries, due to under reporting of the condition in order to avoid social stigma. The utilization of available anti-convulsive drugs in rural communities warrants further investigation. The problems of the epileptic anywhere in the world are compounded by social ostracism. In the context of the rural Limpopo Province of the RSA, this survey indicated a dire need for intensive efforts to disseminate proper information about epilepsy through every means possible, together with improved health care delivery systems which would provide health services to prevent, treat and manage seizures of all kinds, including epileptic convulsions. Primary health care services need to address common causes of seizures, such as obstetric complications, hyperpyrexia, childhood illnesses, malaria and any central nervous system infections. Persons suffering from epilepsy should receive health education and the necessary anti-convulsive drugs. The families and friends of such persons could constitute focus groups to begin to disseminate accurate information about epilepsy, its causes, treatments and complications, and especially the fact that epilepsy is NOT a contagious disease, and that people who assist persons during seizures will NOT be at risk of contracting epilepsy. All health education efforts in the rural areas of the Limpopo Province should continue to emphasize how persons suffering from epilepsy could be helped by community members. However, health care workers should remain aware of the predominant community perception that epilepsy can be transferred to healthy persons during convulsions. Health care workers, especially community health nurses, should act as role models by providing assistance to such persons and by demonstrating that they did not become "infected "with epilepsy as a result of their assistance.

\section{List of references}

AHMAD, K 2000: World Health Organization to improve epilepsy management in Africa. World Health Organization, 13 (gr16) 1706-1709.

BAINS, HS; \& RAIZADA, N 1992: Parental attitudes towards epilepsy. Pediatric Clinics. 16(26): 1487-1490.

BURNS, N \& GROVE, SK 2001: The practice of nursing research: conduct, critique and utilization. Philadelphia: Saunders.

CAROD, FJ 1998: Magical thinking and epilepsy in traditional indigenous medicine. Neurology. 26(154): 1064- 1068.

DANESIMA, 1994: VII Epilepsy and the secondary schools in Nigeria. Tropical and Geographical medicine. ( supplement) 46 (3) 25-27.

CHUNG, MY 1995: Survey of public awareness, understanding and attitudes towards epilepsy in Taiwan. Epilepsia. 36(5):488-493.

DELORENZO, RJ: 1998. Prolonged activation of the NMethyl-D-Aspartate reception oCaZ+ transduction pathway causes spontaneous recurrent epileptiform discharges in hippicamopal neurons in culture. Neurologv Clinics. 95(24): 1482-1487.

EISENSCHENK, MD \& GILMORE, MD 1999: Strategies for successful management of older patients with seizures. Geriatrics. 54(12): 31-46.

HADDOCK, EP 1993: Neurological disorder in Tanzania. Iournal for Health. 68 (9) 112-118

LEE, H \& LEMMER, A 1995: Transient inhibitory seizures mimicking crescendo. Neurology. 40(30(:155-166.

NYAME ,PK \& BIRITWUM, RB 1997: Epilepsy knowledge, attitude and practice in a literature urban population Accra, Ghana. West Africa Journal of Medicine. 16(3) 139145.

OSUNTOKUN, BO 1990: Epilepsy in Ibadan. Nigeria. African Journal of Medical Sciences. 50(1) 100-109.

OXFORD HANDY DICTIONARY 1991: London: Oxford University Press.

PELTZER, K 2001: Perceptions of epilepsy among black students at a university in South Africa. Curationis. 24(2) 62-67.

POLIT,DF \& HUNGLER, BP 1997: Essentials of nursing research methods, Appraisal and utilization . Philadelphia : Lippincott.

UYS, L \& MIDDLETON, L 1997: Mental health nursing: a South African perspective. $3^{\text {rd }}$ ed. Kenwyn: Juta. 